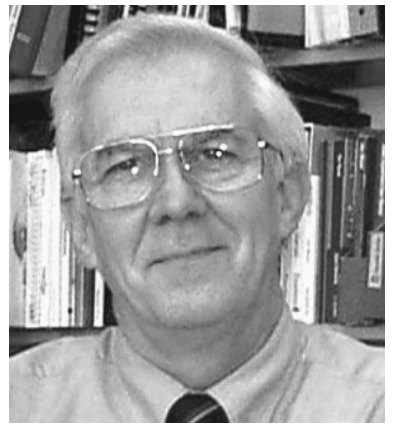

\section{May I have your attention, please!}

Every profession, from optics (my field) to nursing (my wife's) and others, vies for the public interest. The professional societies put out press releases and look for mechanisms through radio, TV, and other public media to get their message out to the public. We want others to recognize that what we do is important; we are competing with other professions for the talent of young people, for money through investment funding, and for awareness on the part of our administration, whether it is government, academic, or industrial. But what provides the needed definition that permits a profession to be heard?

In most cases, it's money. Those professions that command money, command attention, if not respect. Persons in areas such as entertainment, finance, and politics are the ones that gain public attention. In technology, biotechnology has captured the public and it is one area that is not hurting for new recruits. But how can a field such as optics demand that kind of attention?

Consider the nanotechnology initiative that now commands a nice fraction of the US science budget. Nanotechnology researchers get their funding from multiple agencies. And it is considerable. For example, in Fiscal Year 2003 this amounts to about $\$ 710$ million. Of this, \$220 million is part of a total National Science Foundation (NSF) budget of about $\$ 5$ billion; and the Department of Defense (DoD) weighs in with another \$200 million. Someone is paying attention! This was accomplished through a concerted effort by leaders in the field, both inside the US government and in academia, to educate the administration and the Congress to the benefits of nanotechnology. They succeeded in getting new funding written into the budget. So, it was really a bootstrap operation. And it succeeded nicely. Recently, those in optics including SPIE made a similar attempt.

Back in October 2000, Duncan Moore organized a meeting of some of the leadership of OSA and SPIE at the OSA Annual Meeting in Long Beach. The purpose was to investigate the possibility of organizing an effort to establish an initiative similar to the one in nanotechnology. Since Duncan had been the Associate Director for Technology in the Office of Science and Technology Policy
(OSTP) during the Clinton administration, he had watched the process through which nanotech became a buzzword in Washington and a part of the NSF budget. Duncan proposed that optics emulate nanotechnology.

After a series of meetings, OSA and SPIE approved funding to support the initiative by providing the salary and overhead for a full-time project manager responsible for arranging meetings with staff of various administration departments and critical congressional committees. The meetings were intended to engender interest in an optics initiative. Duncan also appeared before many professional organizations asking for additional support. For a number of months a biweekly newsletter was used to keep those interested abreast of the progress in the effort, which became known as NOPI, the National Optics and Photonics Initiative.

It was a difficult time to organize such an initiative. First, there was the change of US administration with the election of Republican George Bush. Then, less than a year later, the attacks of September 11 took place. Since then, homeland security, as it is called, has taken over much of the technology agenda and has made it difficult to pursue anything as general as increased funding for optics.

An initial goal of the initiative was the convening of a White House conference on the Future of Optics, or a similar title. To do this, a fairly rigid schedule had to be set up and followed. Unfortunately, because the confirmation process of those administration staff members in OSTP was prolonged, schedules slipped and it was not possible to bring off a meeting that would help to confer prestige and importance to the initiative. There was eventually a briefing and roundtable discussion on Optics and Photonics held at the White House Conference Center on August 8, which involved a number of staff from various government agencies, but the outcome was inconclusive and a full-blown conference is apparently not in the cards.

Most recently, during its fall meeting, the Board of SPIE decided not to continue support for the initiative. From my own perspective, it would appear that this was an effort whose prospects were decreasing as the months went by. An effort like this has a window when the proposals will be greeted with a receptive skepticism, but it has a "sell-by" date beyond which it is viewed as just 
another lobbying effort. Because the Board saw no clear sign of progress beyond the August meeting, or indications for a better climate to gain support for NOPI, the SPIE Board voted to discontinue support of the initiative.

So where does optics go from here? We are not without resources. At the time the National Academy of Sciences issued the report Harnessing Light, which had been generated by an ad hoc Committee on Optical Science and Engineering (COSE), a loose coalition of optics organizations was formed, called the Coalition on Photonics and Optics (CPO). Over the past few years, CPO developed a number of objectives. Among them was the recognition of optical science and optical engineering as valid career descriptors in government databases.

Another objective, which proved to be difficult to carry out, was to measure the impact of optics in the US economy and particularly in various congressional districts. This was revived when NOPI sprang up. A description of the survey was written and a bid request was prepared and sent to a number of research firms by SPIE's Engineering Science and Technology Policy (ESTeP) committee. The funding "hat" was passed among the CPO members and the project failed to gain the funds needed for the survey. Part of this may have been due to bad economic times and part due to the uncertainty that the survey was worth the information to be gained.

Another effort that had gone through initial planning was a meeting, probably in Washington, to describe and discuss the impact of optics on the US economy and the future of optics in enabling new technology. With the advent of NOPI, this effort was, in effect, supplanted by the plans for a White House Conference. In the interest of full disclosure, I would note that I was the Chair of CPO while the NOPI was being established. I certainly wanted the initiative to succeed, but it definitely put a crimp on CPO's efforts. We sort of stood on the sidelines and watched the parade pass by.

As I watched, I was somewhat skeptical of the process that was unfolding. What concerned me during this time, and still bothers me today, is that the same approach was being used to gain attention that had been used for nanotechnology. But there are substantial difference in the histories of optics and nanotechnology. In the latter case, the field is so new and revolutionary that increases in efforts will almost certainly yield new and exciting results. Whereas optics is an old field with many developed subspecialities that have become the basis for new technologies (e.g., fiber optics), it is much harder to locate the points of purchase that provide needed leverage for drastic changes in funding. For example, an exercise was con- ducted to generate a series of Grand Challenges for the optics of the future. The resulting list did not, to my mind, contain a glittering array of examples that would entice the imaginations of politicians and administrators. We in optics have the very difficult problem of explaining to the world that this tremendous enabling, but invisible, technology of the 21 st century deserves recognition as an economic force and a source of rewarding jobs.

Because NOPI had no formal organization, such as a steering committee, budget, and bylaws, it is not clear whether the Initiative has lost its initiative. However, the SPIE Board's withdrawal of funding will put a serious crimp in NOPI's future. But that does not mean that the effort to gain recognition for optics should be abandoned. NOPI has increased governmental interest in optics considerably beyond what we have had till now. And that is an important part of what we do in the furture.

One organization in place that could pick up and run with this is the CPO. To do so, however, the coalition must get off the sidelines and change from a group for exchanging information on optics to an organization with an active agenda. We are now more than five years beyond the National Academy report, Harnessing Light, and the shape of optics has changed considerably. There is still a need to describe the impact of optics on the economy and list the difficulties we face in the next decade. This effort may not gain the targeted chunk of new funding that was the goal of NOPI. But if we are to make our case for increased support from the new funding that will be available in NSF, DoD, and other agency budgets next year, we must get and keep the attention of the public and their representatives.

Although the above discussion was concerned with US government funding, similar processes and programs exist in many of the countries where many SPIE members reside. For example, the publication of Harnessing Light led Germany and other countries to conduct similar studies. They resulted in more support for optics programs there than they ever did in the US. As SPIE Executive Director Eugene Arthurs noted, "The US nanotech initiative was the best thing that ever happened to world nanotech funding and it is great to see how the Japanese level of funding, derived from the US effort, is used to ratchet up the US level to stay ahead." So, efforts in optics by groups like SPIE's ESTeP committee or the CPO, which SPIE supports, can have a real impact in other countries.

Donald C. O'Shea Editor 